
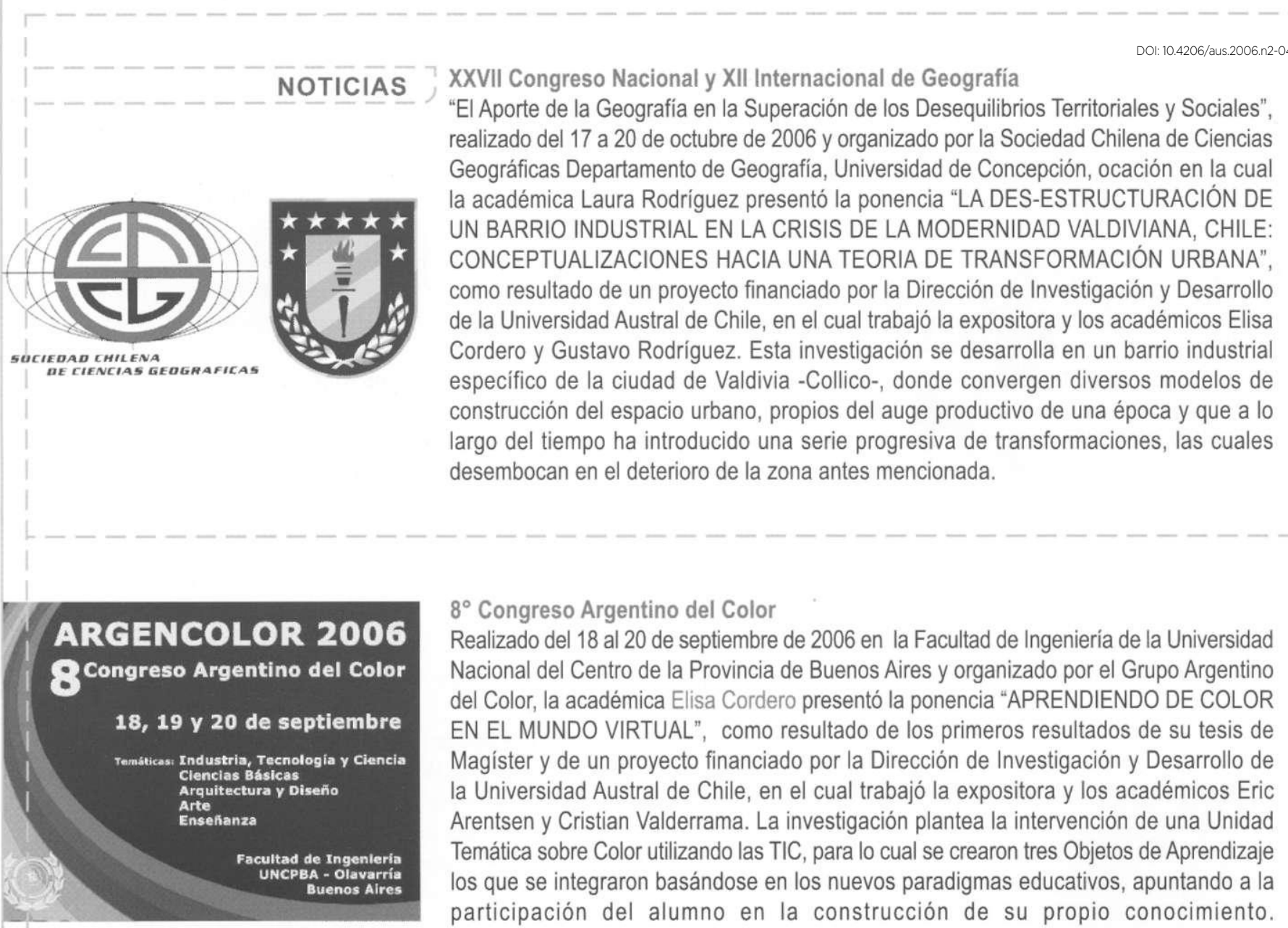

$8^{\circ}$ Congreso Argentino del Color

Realizado del 18 al 20 de septiembre de 2006 en la Facultad de Ingenieria de la Universidad Nacional del Centro de la Provincia de Buenos Aires y organizado por el Grupo Argentino del Color, la académica Elisa Cordero presentó la ponencia "APRENDIENDO DE COLOR EN EL MUNDO VIRTUAL", como resultado de los primeros resultados de su tesis de Magíster y de un proyecto financiado por la Dirección de Investigación y Desarrollo de la Universidad Austral de Chile, en el cual trabajó la expositora y los académicos Eric Arentsen y Cristian Valderrama. La investigación plantea la intervención de una Unidad Temática sobre Color utilizando las TIC, para lo cual se crearon tres Objetos de Aprendizaje los que se integraron basándose en los nuevos paradigmas educativos, apuntando a la participación del alumno en la construcción de su propio conocimiento.

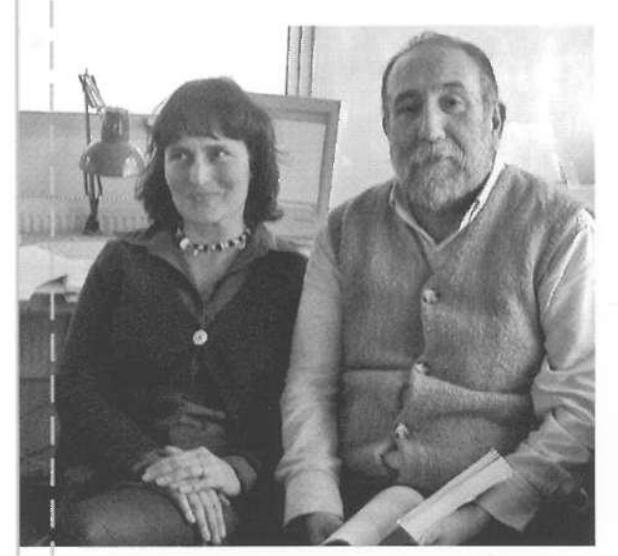

Título de Magister

En mayo del 2007, los académicos Elisa Cordero y Juan Carlos Olivares recibieron su título de Magister en "Modelado del conocimiento para entornos virtuales educativos", dictado por la Facultad de Ciencias de la Ingenieria y la Facultad de Filosofia y Humanidades. La tesis presentada por la académica Elisa Cordero, con el título "DISEÑO DE UNA METODOLOGÍA PARA LA ENSEÑANZA DEL COLOR" presenta una intervención pedagógica que reestructura la metodologia de enseñanza-aprendizaje de una Unidad Temática, apoyándola con Objetos de Aprendizaje y TIC, y construyendo un plan de trabajo coordinado con el Taller de Arquitectura. La tesis presentada por el académico Juan Carlos Olivares, con el titulo "LOS ARFACTOS DEL CIBERSHAMÁN: UNA PERSPECTIVA POSMODERNA EN LA ENSEÑANZA VIRTUAL DE LA DIFERENCIA CULTURAL EN LA ARQUITECTURA", donde presenta en una perspectiva posmoderna, la determinación de los modos y/o maneras de representar la alteridad en una herramienta de enseñanza virtual, que demandan la ejecución de un trabajo participativo mancomunado.

xxiII

international Biometris Conference

Montrisal, Quebec canada

Juty 16. 21, 2006

\section{International Biometric Conference}

Realizado en Montreal, Québec, Canadá, fue presentado un poster con el título "Gender, Science and Education in Chile: Discovering gender in the pedagogic speech (formal study plan) of the third cycle education, Universidad Austral de Chile 2003-2004" realizado por un grupo de académicas investigadoras de la Universidad Austral de Chile, entre las que se encuentra Laura Rodriguez, perteneciente al Instituto de Arquitectura y Urbanismo de esta Universidad. La investigación, mediante una metodología cuantitativa y cualitativa, explora el enfoque de género que se da en las distintas cátedras de las carreras al interior de la Universidad Austral de Chile. 


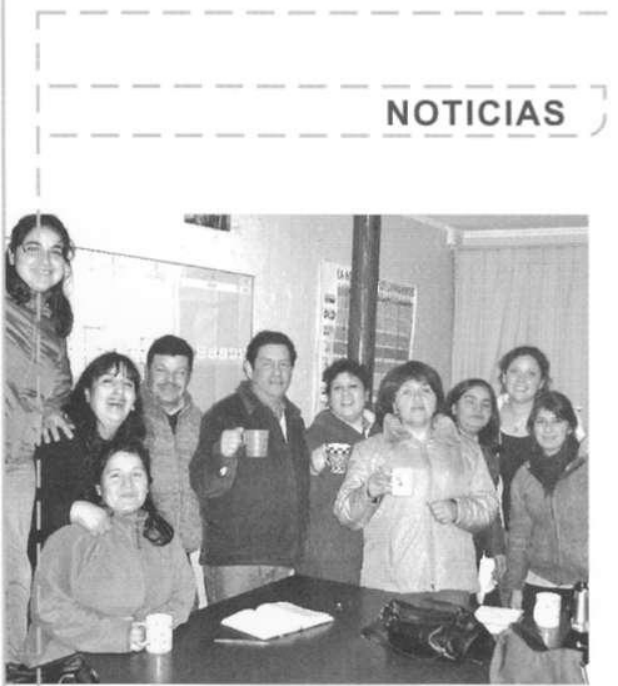

Proyecto de Erradicación Comité de Vivienda Nueva Región

La creación del proyecto "Comité de vivienda nueva región" surge por iniciativa de las familias que participaban en el comité de vivienda Elemental, que debido a factibilidades sociales y económicas, no logró ejecutarse. Para la conformación de este nuevo comité se buscaron integrantes de otros campamentos y casos sociales derivados de SERVIU Valdivia, llegando a 135 familias. El terreno donde se localizarán las nuevas viviendas se emplaza en el sector Barrio Estación, en Av. Ecuador, perpendicular a Avenida Lynch. Hoy las familias se encuentran prontas a recibir sus subsidios, iniciando la etapa de habilitación social, plan que entrega las herramientas para la conformación de un barrio sostenible, y en donde tres estudiantes de Arquitectura de la UACh, Macarena Martel, Álvaro Lefián y Daniel Muñoz realizarán talleres de habitabilidad cuya finalidad es entregar los recursos técnicos que faciliten el proceso de ampliación y la promoción de temáticas de habitabilidad en la vivienda, que mejoren el confort en su interior. Además, la realización de estos talleres permitirá a dos de estos estudiantes obtener los elementos necesarios para proyectar la futura sede comunitaria del nuevo barrio, la que con fondos obtenidos de terceros podrá contar con nuevos programas como sala cuna, biblioteca y jardin infantil.

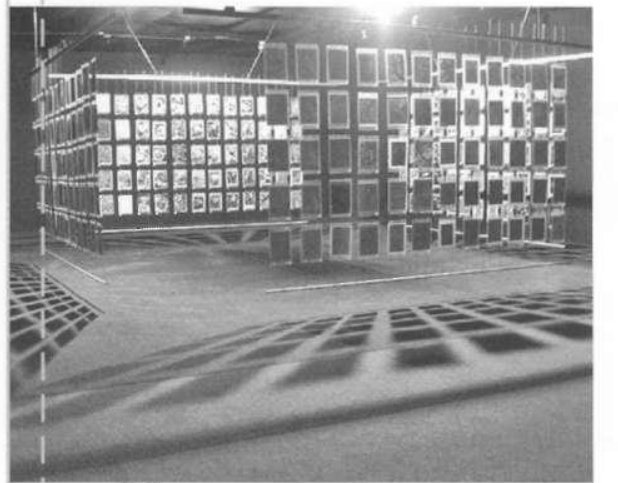

\section{Exposición de Manuel Casanueva}

"Entre el dibujo y la imagen", dibujos de arquitecto, es el nombre de la exposición que presentó en el Museo de Arte Contemporáneo de Valdivia el arquitecto Manuel Casanueva. Más que dibujos, (en el sentido de predominio de la "forma"), en la exposición está presente el color y forma. La exposición es además una instalación espacial en que uno queda inmerso en una especie de interior virtual, que podría ser tomado como una habitación. O sea, podríamos decir que estamos dentro de una habitación llena de color. Según el expositor, "Esta muestra da cuenta de un período arquitectónico post - obra de arquitectura. La pintura extiende el color, en tanto que este dibujo lo contracta. Lo que esta hipótesis trata es el margen estrecho entre la factura (mano) y el aporte técnico (computador). En la arquitectura idea y realización son de igual categoría puesto que etimológicamente configuran la palabra arquitectura. Lo que ha ocurrido es que hoy en dia predomina lo tecnológico, confundiéndose con la idea y más aún con la técnica. El estrecho margen mencionado es una ecuación entre oficio e implemento." La exposición se compone de una serie de 6 capítulos que dan cuenta de diversos conceptos como son el tema cinético, el predominio del dibujo sobre la imagen, la validez y el no valor, figura y fondo, las espirales, y la negación a la clonación. La combinación de colores de estas obras, es el criterio de temperie cromática en la Hospedería del Errante. (http://www.profesores.ucv.cl/manuelcasanueva/)

\section{Ernst Kasper}

Arquitecto y profesor, quien desde el año 2000 visita semestralmente nuestra Escuela e Instituto en calidad de examinador externo, ha sido designado, a partir del año 2007, Profesor extraordinario categoría I, de la Facultad de Ciencias de la Ingeniería, como reconocimiento a su aporte a la visión que los profesores han desarrollado sobre la arquitectura y el urbanismo en la región y por su gran entrega al proceso de aprendizaje de nuestros estudiantes. Ernst Kasper nació el año 1935 en Trier, Alemania, y estudió arquitectura en Aachen, donde tiene su oficina profesional. Durante su carrera ha ganado innumerables concursos de arquitectura, muchos de los cuales han sido construidos, especialmente en el área educacional. El año 1971 fue nombrado profesor en la Kunstakademie de Düsseldorf, donde el 2000 pasó a ser profesor emérito. Durante cada visita a nuestro Instituto y Escuela, el profesor Kasper realiza correcciones en los distintos Talleres y charlas en que nos muestra sus últimas obras realizadas en Alemania. (http://www.ernst-kasper.de/) 


\section{NOTICIAS}

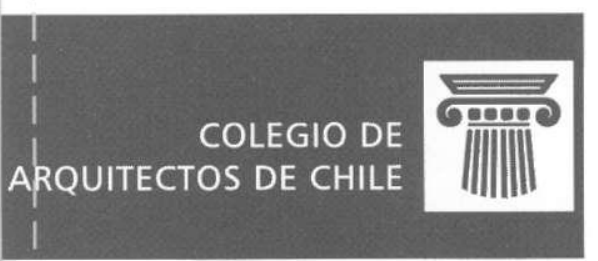

Nueva directiva delegación C.A. Valdivia

El pasado 20 abril, dentro del marco de las últimas elecciones del Directorio del Colegio de arquitectos de Chile A.G., fueron elegidos Directores de la Delegación Zonal Valdivia para el periodo 2007-2008, los académicos del Instituto de Arquitectura y Urbanismo de la Universidad Austral de Chile, Maritza Lobos Saavedra y Roberto Martínez Kraushaar quienes asumen en los cargos de presidente y secretario respectivamente.

Dentro de los desafíos del nuevo Directorio se encuentra la organización del XXI Congreso Nacional de Arquitectos en la ciudad de Valdivia, para el año 2009 y la reactivación del Servicio de Asistencia Técnica, iniciativa que se está implementando a nivel nacional.

Hans Fox

El arquitecto y académico de la Universidad de Santiago, ofreció un curso a los académicos del Instituto de Arquitectura y Urbanismo de la UACH, con el tema "Principios y Métodos para el diseño de programas curriculares y estándares de evaluación en arquitectura". Fox expuso claramente su tesis sobre la importancia que tiene un adecuado diseño de programa, el cual posea como un hilo conductor, el proceso evaluativo de principio a fin. Esto se vuelve especialmente importante en el momento final de los talleres, en que alumno y profesor pasan por diferentes etapas que, de conocerlas en forma consciente, hacen mucho más claro el proceso de creación y de evaluación.

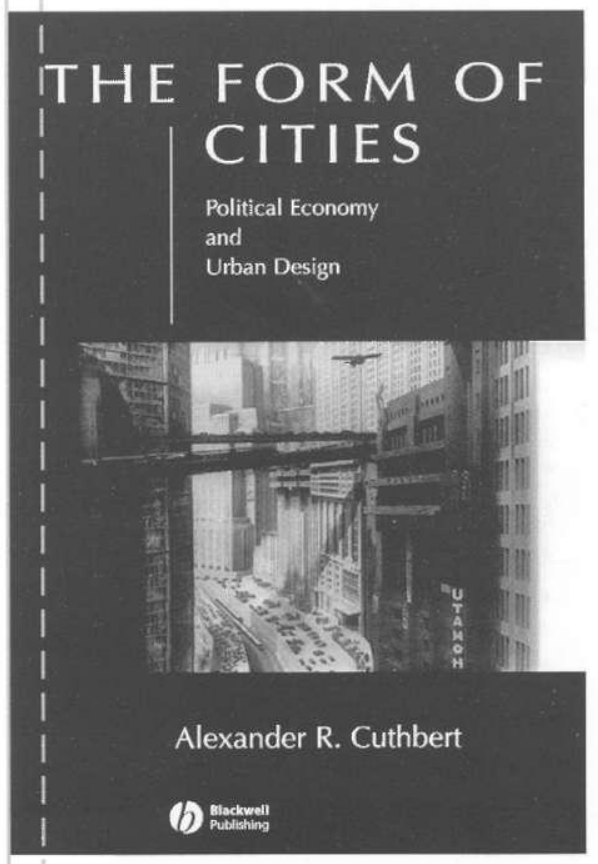

Título: THE FORM OF CITIES Political economy and urban design

Autor (es): Alexander R. Cuthbert

Editorial: Blackwell Publishing

Lugar: USA, UK y Australia.

Año: 2006

$\mathrm{N}^{\circ}$ de páginas: 304

Formato: $17,5 \times 24,5 \mathrm{cms}$.

El trabajo desempeñado por Cuthbert en este libro es un extraordinario análisis no sólo acerca del estado de las artes en cuanto a teoría urbana, también nos entrega una visión crítica del vínculo entre la economía política y el diseño urbano. La ciudad, de acuerdo a lo expresado en el libro, no sólo esta sujeta al escrutinio histórico, es un reflejo de un discurso filosófico que mediante una producción simbólica da cuenta de relaciones de clase, de género entre otras categorias, mediatizadas por aspectos culturales y politicos. Cuthbert demuestra un tremendo dominio al remover toda ingenuidad del discurso urbano, demostrando la profunda interconexión entre la forma de una ciudad y la ideología predominante. De esta manera el libro aborda el diseño urbano desde la perspectiva de la transmisión del significado urbano en formas urbanas específicas. Es ante todo una herramienta para entender el diseño urbano más que un libro acerca de como realizarlo.

Si bien es cierto la perspectiva económica esta presente en este libro, no se plantea especificamente en un capitulo; este trabajo se organiza básicamente en tres secciones, teoria, historia y filosofía. Similarmente la politica, la cultura y el género abordan la dimensión social y las siguientes categorias, medio ambiente, estética y tipologias se relacionan con el asunto formal. En última instancia el denominado capítulo de práctica discute algunas necesarias consideraciones entre la educación, la investigación y la práctica profesional propiamente tal. 